\title{
Research on Construction Safety Management Based on BIM Taking the Direction of Construction Engineering as an Example
}

\author{
Na Xiong ${ }^{1, a}$ and Jian Tang ${ }^{2, b}$ \\ ${ }^{1}$ Nanchang Institute of Technology, No 901 Hero Avenue, Changbei Economic Development Zone, \\ Nanchang, Jiangxi, China (330044) \\ ${ }^{2}$ Jiangxi Science \& Technology Normal University, No. 605, Fenglin Road, Changbei Economic \\ Development Zone, Nanchang, Jiangxi Province (330013) \\ a289610964@qq.com, b176024108@qq.com
}

Keywords: Optimization of construction safety; Safety management; Building information model ( BIM ); Hazard identification

\begin{abstract}
This paper combines the building information model technology and the construction safety management, and integrated safety management of time and space for the construction of construction engineering, the application of building information model technology in construction safety management is realized. And put forward building information model technology security inspection system based on hazard identification and dynamic virtual construction, the innovation of building information model technology applied in the safety management of building engineering is realized.
\end{abstract}

\section{Introduction}

With the development of the national economy, the improvement of people's demand for spiritual and material culture, the volume and scale of buildings are becoming larger and larger, with the increase of construction scale and management difficulty, the construction safety management of construction engineering faces greater challenges. Safety accidents occur frequently in construction engineering have caused serious threat to the people's life and property, new challenges to traditional security management methods are presented, how to effectively improve this situation has become a problem that we must face and solve at present.

With the rapid development, popularization and application of building information model ( BIM ) technology in China's construction industry, it is beneficial to improve the management mode in the construction field,to promote technological innovation in the construction industry. BIM technology has been widely used in the fields of professional collaborative design, architectural performance analysis, engineering quantity statistics, construction virtual simulation, system operation and maintenance, etc.In the project management, the greatest advantage of BIM is that in the early project management can find and solve the problems that may encounter in the construction process, and the collaborative work and management problems between different specialties.

Through the application of BIM technology in the construction safety management process, this paper analyzes the advantages and disadvantages of the construction safety management and traditional safety management mode based on the building information model technology, and explores the theory and practice of the application of building information model technology in the construction phase safety management. The possible hazard source $\mathrm{w}$ and the main hazard sources in the construction process are analyzed, and the construction safety management model based on BIM technology is established. 


\section{Construction Safety Management of Construction Engineering Based on Building}

\section{Information Model}

Construction Risk Analysis. From the statistical analysis of the construction types of construction accidents in our country in 2010 - 2015, it can be concluded that the main types of construction accidents in China are:high-altitude falling accident, collapse accident, object strike accident, crane injury accident and other accidents. The biggest threat to public safety of construction engineering is the safety accident at the entrance and the adjacent area, because the number of deaths in the accident is the highest. Therefore, the corresponding safety measures must be taken in the construction to make the safety accidents less.

The Technology and Application of Building Information Model. BIM is a detailed digital expression of information about a project construction project. The BIM model is highly integrated with information. This information is in the form of 3D, 4D, or even 5D that stored in the model. Parametric modeling, however, refers to the creation of a model by coordinating and changing the relationships between all of the diagram elements in the project.Parameterized methods have a great advantage in the improvement of coordination and modeling efficiency of the project, the main reason is that any changes to the model in the project at any time will be coordinated throughout the project. The process of parameterized modeling is through the analysis of the actual project's business requirements, which leads to the related BIM applications, such as the application of the design phase and the application of the construction phase.

Construction Engineering Construction Safety Management Based on Building Information Model Technology. The construction safety management model based on building information model has adopted the theory of hazard source. According to hazard theory, The root cause of the construction safety accidents is because there are dangerous sources in the construction process, and the method to prevent the construction safety accidents is to eliminate or control the hazards source existing in the construction process. In other words, The construction safety management model of building construction is based on the premise that the hazard source is identified.

Hazard source identification methods has intuitive experience analysis methods and system safety analysis methods. System safety analysis includes safety checklist, accident tree analysis, prehazard analysis and causal analysis. Safety inspection table method is a kind of system security analysis, It is the manager who compares the information of the components of the project according to the security check form and grades the safety measures, When the detection measure does not meet the specified area to deduct a certain fraction, the place where deducting the score is generally the place where the hazard source needs to be identified.

The traditional SCL (security checklist method) is described by the text of the inspection project, can not be intuitively and accurately reflect the construction process of dangerous source information, and even some text description may cause safety manager and Construction technician of the understanding of bias, will affect the construction safety; And in SCL, the conclusion about hazard identification is static, immutable, can not reflect the dynamic construction techniques, and does not contribute to the optimization and improvement of construction safety. The visualization of BIM technology can make the description and display of the inspection items of the hazard more intuitive and more accurate to the hazard;Simulation of the construction process and hazard sources can be more intuitively demonstrated in the construction process of the changes in the source of danger and the relationship between the construction process; The optimization of BIM technology can make the identification of dangerous sources dynamic and changeable, which can better reflect the situation in the construction and is conducive to the optimization and improvement of construction safety. Therefore, based on the identification of dangerous sources, it is suggested that construction safety management should help to improve the construction safety management.

In the process of BIM modeling, hazard information is built into the model as data input. The hazard database stores the types of hazards, the location of the damage, the hazards that are generated, the method of eliminating the source of the hazard, and the form of the database.Through 
this database, the construction safety management personnel during the construction safety programming process and the construction safety education training personnel in education training design process, who are based on different construction sites, to search the type of the search hazard source and the corresponding solution and design the corresponding scheme. Hazard source database based on BIM that is a combination of database technology and BIM technology, It integrates hazardous source data into specific model information and USES the BIM platform to use and operate the information of hazard and through the BIM platform to use and operate information of hazard source. It makes the use of information of hazard source more convenient, more targeted and more intuitive.

After the model is completed, the model can be optimized .The optimization part mainly aims at the construction process of safety management optimization, including the construction process optimization and construction safety optimization two parts. Through Revit, Navisworks and Project, real-time walkthrough of input complex parametric model and project information is reviewed, and the construction process and security management are optimized. Optimization part mainly through the quality assurance, safety assurance and civilized construction guarantee, to optimize the construction process and construction safety.

Through the optimization of construction process and safety management, construction scheme and optimized design, and makes the recognition on the construction safety risks more effectively, to improve construction safety plan more reasonable, the better methods of safety education and training.

\section{Conclusion}

This paper is based on BIM technology, combined with the construction safety management status and hazard analysis, elaborated the BIM technology construction safety management based on the advantages of BIM technology in building engineering construction safety management based on the established model of construction safety management of construction project based on BIM.

Through the study of this paper, we can get the following conclusions:

We should apply the BIM technology to construction safety management.

The main performance of BIM in construction safety management is five aspects, such as visualization, coordination, simulation, optimization and drawing. These advantages can make the construction of safety management process more intuitive, more practical scheme of construction safety management, coordination between different majors more smooth, optimize the construction management plan is more convenient, makes the construction of safety management more convenient, fast, high efficiency, can greatly improve the construction safety management level. Therefore, BIM technology should be applied to the safety management of construction projects.

The construction safety management model based on BIM is obtained.

On the basis of hazard analysis and BIM model as the platform and construction schedule as the link, the construction safety management model based on BIM technology is established. It provides reference for the practice of construction safety management.

Through the analysis of the dangerous sources, the types of the main hazard sources in the construction process of our country's construction projects are sorted out, the causes and the countermeasures are brought out.

\section{References}

[1] Z.Z.Hu,J.P.Zhang and X.L.Zhang, System Safety Analysis Method to Support the Construction of Construction Safety Information Model Based on 4D[J],Engineering Mechanics, Vol.50(2010)No.6,pp.195-196.

[2] Alex Behriger, Salman Azhar, BIM for Construction Safety:A Case Study[J].2013.

[3] J.P.Zhang, X.Li,J.R.Lin and G.W.Yan,Application of BIM in Construction[J].Construction Technique, Vol.41(2012)No.371,pp.11-14.

[4] Y.Li and C.S.Guan. The Information Management Mode and Strategy of Engineering Project 
Based on BIM Technology[J].Journal of Engineering Management, Vol.04(2012)pp.17-21.

[5] J.H.Cheng and H.Wang. Application and Popularization of BIM Technology in Project Management[J].Construction Technique,(2012)No.16,pp.18-21.

[6] J.P.Li. Construction Risk Identification and Safety Management Research[D].Tianjin, Tianjian University(2007)

[7] Qi J,Issa RRA, Hinze J,et al. Integration of Safety in Design Through the Use of Building Informaticm Modeling. American Society of Civil Engineers,(2014)No.416. 